$630 \cdot 40$

\title{
aparato registrador de la retracción por secado
}

(Appareil pour enreglstrer le retrait au séchage)

F. MOORE. W. NOBLE

De: "Transactions of the British Ceramie Society», vol: 55, núm. 9, septiembre 1956, pág. 571*

El aparato descrito permite registrar la retracción por secado de un ladrillo normal o de cualquier otra pieza cerámica; lo mismo se puede colocar en una vagoneta de un secadero túnel, en un secadero de cämaras, etc.

El ladrillo se dispone sobre una base de latón. En sus extremos se apoyan unos discos de latón, de $9 \mathrm{~mm}$ de dímetro; dichos discos se encuentran articulados sobre dos brazos de palanca, de $5 \mathrm{~cm}$, fjos a unas plezas, que a su vez se hallan unidas a la base mediante una charnela. Paralelamente se encuentran otros dos brazos, de $10 \mathrm{~cm}$, provistos de una pequeña polea: también están unidos a la misma base. Como los segundos brazos indicados son dos veces más largos que los primeros, las poleas que llevan recorren un camino dos veces mayor que los discos, como consecuencia de la retracción del ladrillo.

Los discos se mantienen contra el ladrillo mediante un cable, que por su otro extremo se halla unido a un tambor provisto de resorte. La tensión del hilo debe ser la suflciente para mantener el contacto de los discos sin ejercer una presión exagerada. E1 hllo está también unido a un carro que se desplaza a lo largo de un eje fijo. A medida que el ladrillo experimenta la retracción, el hilo arrastra al carro, cuyo desplazamiento es cuatro veces mayor. Este carro acciona un pantógrafo, provisto de una pluma dispuesta delante de un tambor registrador. De este modo, la retracción representada en el diagrama en función del tiempo se ha amplificado ocho veces.

En los ladrillos que se secan, existe siempre un gradiente de humedad entre la superficie y el núcleo; este gradiente aumenta con la velocidad de secado. El exterior, cuya retracción es mayor, se encuentra sometido a esfuerzos de tracción, mientras que el núcleo se halla sometido a compresión. Si las tensiones resultantes son superiores a la resistencia mecánica de los ladrillos crudos, aparecen grietas.

Puede ponerse de manifiesto la exlstencla de tales tensiones sin más que comparax la curva de la retracción en función del tiempo, determinada experimentalmente, con la curva media calculada de acuerdo con la pérdida de peso que corresponde al agua evaporada. De este modo

* En aL'Industrle Ceramiquew, núm. 481, diciembre 1955, pág. 308. 
se ha comprobado, en el caso de una arcilla poco plástica, que ni el secado demasiado rápido ni el demasiado lento permite anular las tensiones antes de que el ladrillo haya alcanzado la consistencia del cuero. En las arclllas muy plásticas, el gradiente de humedad es más pronunclado y la diferencia, entre las dos curvas es más pronunciada.

Los autores indican que, en una fábrica, este tnstrumento ha servido para comparar dos secaderos-túnel, que los ladrillos atraviesan en setenta y dos horas. Según las curvas registradas, los productos alcanzan la consistencia del cuero a las treinta y sels horas, en el primero, y a las sesenta y seis horas, en el segundo. Por consigulente, se podría casi duplicar la producción del primer secadero; además, se podría mejorar el funclonamlento del segundo secadero si se elevase la temperatura y la cantidad de aire.

En otra fábrica se ha comprobado que la velocidad de secado no es la misma en la parte alta que en la baja de las vagonetas; y asimismo, se han observado variaciones debidas a la preparación, por adelantado, de las vagonetas que se introductrán el domingo en el secadero. Según las curvas obtenidas, los ladrillos introducidos presentan un contenido variable de agua, el aire se encuentra saturado a la entrada, y sería necesarlo que la aportación de calor fuese supertor para que esta zona recuperase de nuevo su eficacia; a la sallda, los ladrillos se encontratán más secos.

S. F. S. 